\title{
Factors Affecting Isoflavone Content in Soybean Seeds Grown in Thailand
}

\author{
Supanimit Teekachunhatean, ${ }^{1,2}$ Nutthiya Hanprasertpong, ${ }^{1}$ \\ and Thawatchai Teekachunhatean ${ }^{3}$ \\ ${ }^{1}$ Department of Pharmacology, Faculty of Medicine, Chiang Mai University, Chiang Mai 50200, Thailand \\ ${ }^{2}$ Center of Thai Traditional and Complementary Medicine, Faculty of Medicine, Chiang Mai University, Chiang Mai 50200, Thailand \\ ${ }^{3}$ School of Crop Production Technology, Institute of Agricultural Technology, Suranaree University of Technology, \\ Nakhon Ratchasima 30000, Thailand
}

Correspondence should be addressed to Supanimit Teekachunhatean; steekach@med.cmu.ac.th

Received 11 July 2013; Accepted 5 September 2013

Academic Editor: Patrick J. Tranel

Copyright (C) 2013 Supanimit Teekachunhatean et al. This is an open access article distributed under the Creative Commons Attribution License, which permits unrestricted use, distribution, and reproduction in any medium, provided the original work is properly cited.

\begin{abstract}
Soybeans are the most common source of isoflavones in human foods. The objectives of this study were to determine the effects of Thai soybean variety, planting date, physical seed quality, storage condition, planting location, and crop year on isoflavone content, as well as to analyze the relationship between seed viability and isoflavone content in soybean seeds grown in Thailand. Isoflavone content in Thai soybeans varied considerably depending on such factors as variety, physical seed quality, crop year, planting date (even in the same crop year), and planting location. Most varieties (except for Nakhon Sawan 1 and Sukhothai 1) had significantly higher isoflavone content when planted in early rather than in late dry season. Additionally, seed viability as well as long-term storage at $10^{\circ} \mathrm{C}$ or at ambient condition seemed unlikely to affect isoflavone content in Thai soybean varieties. Isoflavone content in soybean seeds grown in Thailand depends on multiple genetic and environmental factors. Some varieties (Nakhon Sawan 1 and Sukhothai 1) exhibited moderately high isoflavone content regardless of sowing date. Soybeans with decreased seed viability still retained their isoflavone content.
\end{abstract}

\section{Introduction}

Soybeans (Glycine max (L.) Merrill) are the most common source of isoflavones in human foods, especially in many Asian countries. Isoflavones represent the most common group of phytoestrogens, which are structurally similar to estradiol-17 $\beta$, the most potent mammalian estrogen [1]. Isoflavones exhibit three aglycone structures (daidzein, genistein, and glycitein), which enter into three $\beta$-glycoside conjugates (daidzin, genistin, and glycitin), each with a corresponding acetyl and malonyl glycoside conjugate (Figure 1). Since glycitein and its glycoside conjugates account for less than $5-10 \%$ of the total isoflavones in soy-based products, most studies have focused on daidzein and genistein and their respective glycoside conjugates $[2,3]$. This study adopted a similar approach.

Epidemiological and clinical studies of postmenopausal women have suggested that isoflavones decrease their risk of osteoporosis and cardiovascular diseases while alleviating vasomotor symptoms [4-8]. However, the beneficial effects of isoflavones remain controversial. Discrepancies in overall study design, differences in isoflavone type and dosage, variations in participant demographics, and differing outcome parameters might all have contributed to contradictory study results [9]. However, a consistent finding is that the selection of isoflavone-rich soybeans as raw materials in the manufacturing of soy or soy-based products is a crucial factor in their clinical effectiveness.

Isoflavone content in soybeans depends on both genetic and environmental factors, including climate, planting location, crop year, planting dates within a given crop year, and storage conditions [10-13]. Although findings exist for a variety of genotypes in a variety of environments, there are no firm data regarding the isoflavone content of Thai-certified soybeans grown in Thailand. This study remedied that 


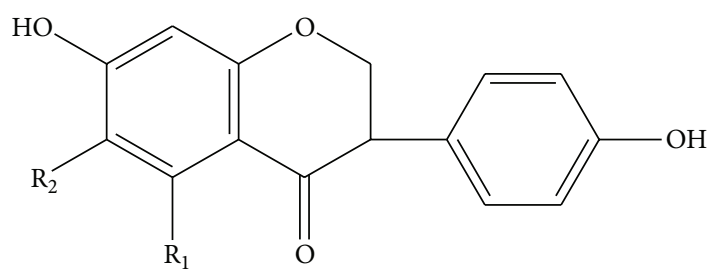

\begin{tabular}{ccc}
\hline Aglycones & $\mathrm{R}_{1}$ & $\mathrm{R}_{2}$ \\
\hline Daidzein & $\mathrm{H}$ & $\mathrm{H}$ \\
Genistein & $\mathrm{OH}$ & $\mathrm{H}$ \\
Glycitein & $\mathrm{H}$ & $\mathrm{OCH}_{3}$ \\
\hline
\end{tabular}

(a)

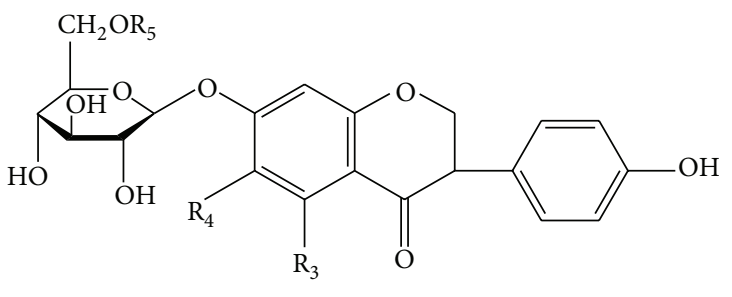

\begin{tabular}{cccc}
\hline Glycosides & $\mathrm{R}_{3}$ & $\mathrm{R}_{4}$ & $\mathrm{R}_{5}$ \\
\hline Daidzin ( $\beta$-glycoside) & $\mathrm{H}$ & $\mathrm{H}$ & $\mathrm{H}$ \\
Genistin ( $\beta$-glycoside) & $\mathrm{OH}$ & $\mathrm{H}$ & $\mathrm{H}$ \\
Glycitin ( $\beta$-glycoside) & $\mathrm{H}$ & $\mathrm{OCH}_{3}$ & $\mathrm{H}$ \\
$6^{\prime \prime}$-O-Malonlydaidzin & $\mathrm{H}$ & $\mathrm{H}$ & $\mathrm{COCH}_{2} \mathrm{COOH}$ \\
$6^{\prime \prime}$-O-Malonlygenistin & $\mathrm{OH}$ & $\mathrm{H}$ & $\mathrm{COCH}_{2} \mathrm{COOH}$ \\
$6^{\prime \prime}$-O-Malonlyglycitin & $\mathrm{H}$ & $\mathrm{OCH}_{3}$ & $\mathrm{COCH}_{2} \mathrm{COOH}$ \\
$6^{\prime \prime}$-O-Acetyldaidzin & $\mathrm{H}$ & $\mathrm{H}$ & $\mathrm{COCH}_{3}$ \\
$6^{\prime \prime}$-O-Acetylgenistin & $\mathrm{OH}$ & $\mathrm{H}$ & $\mathrm{COCH}_{3}$ \\
6 6-O-Acetylglycitin & $\mathrm{H}$ & $\mathrm{OCH}_{3}$ & $\mathrm{COCH}_{3}$ \\
\hline
\end{tabular}

(b)

Figure 1: Structure of isoflavones in the forms of aglycones (a), $\beta$ gly-cosides, $6^{\prime \prime}$-O-acetyl- $\beta$-glycosides, and $6^{\prime \prime}$ - $O$-malonyl- $\beta$-glycosides (b).

deficiency by investigating 14 Thai soybean varieties, including Chiangmai 60, one of the most popular varieties.

The study consisted of two basic parts. The first part sought to determine the isoflavone content of the 14 varieties grown at the same location but with variations in planting date, physical seed quality, and storage condition. The second part targeted sound seeds of Chiangmai 60. Specifically, it examined the effects of planting location and crop year on total isoflavone content and analyzed the relationship between isoflavone content and seed viability.

\section{Materials and Methods}

2.1. Description and Preparation of 14 Soybean Varieties Grown at the Same Location. Covering a broad range of pedigrees and physical types, the 14 soybean varieties represented the vast majority of soybeans grown in Thailand. In alphanumerical order, they were Chiangmai 2, Chiangmai 5, Chiangmai 60, Chakkrabhanhu 1, KKU 35, Nakhon Sawan 1, SJ 1, SJ 2, SJ 4, and SJ 5, Srisamrong 1, Sukhothai 1, Sukhothai 2, and Sukhothai 3. Significant characteristics are summarized in Table $1[14,15]$.

The 14 soybean varieties were collected from the Suranaree University of Technology (SUT) Farm, located in Nakhon Ratchasima Province in northeastern Thailand about $250 \mathrm{~km}$ east of Bangkok $\left(14^{\circ} 53^{\prime} \mathrm{N}, 102^{\circ} 01^{\prime} \mathrm{E}\right)$. All seeds were grown at the farm itself using Lob Buri Series soil, black in color with clay texture and high holding capacity. Measuring $7.2 \mathrm{pH}$, the soil contained $3.35 \%$ organic matter, $36.5 \mathrm{mg} / \mathrm{kg}$ of $\mathrm{P}_{2} \mathrm{O}_{5}$, and $197 \mathrm{mg} / \mathrm{kg}$ of $\mathrm{K}_{2} \mathrm{O}$. All planting took place in dry season on three dates: 19 December 2009, 26 December 2009, and 15 January 2010.

Cultural practice was the same for all varieties on all dates. Each variety occupied a two-row plot $10 \mathrm{~m}$ long and $0.5 \mathrm{~m}$ apart. The seeds were planted 3 per hill without rhizobial inoculant. Fourteen days after planting, the seedlings were thinned to 2 plants per hill. The crop received fertilizer at 15 and 35 days after planting at the rates of 18.75, 50.00, and $18.75 \mathrm{~kg} / \mathrm{ha}$ of $\mathrm{N}, \mathrm{P}_{2} \mathrm{O}_{5}$, and $\mathrm{K}_{2} \mathrm{O}$, respectively. Drip irrigation was applied over the planting season. Hand weeding and application of appropriate chemicals controlled weeds, diseases, and pests. The plants were hand-harvested at R8 maturity (brown pod) and sun dried. Depending on planting date and varietal type, harvesting occurred between 8 March and 28 April 2010. Threshing was done manually, followed by winnowing for seed precleaning.,

The dried seeds of each soybean variety and planting date were divided according to physical quality into three categories: undersized, unsound, and sound. Undersized seeds were separated by oblong screens with mesh measuring $3.8 \mathrm{~mm} \times 19.1 \mathrm{~mm}$. After the removal of these substandardsized seeds, the remainder was visually inspected and handsorted for damage (mechanical, insect, and fungal) and for immaturity (green seeds). After the removal of these "unsound" seeds, the remaining portion was characterized as "sound" seeds, suitable for planting or human consumption. All dried seeds of all categories were then refrigerated at $10^{\circ} \mathrm{C}$ in heat-sealed plastic bags until analysis for isoflavone content in mid-August 2010.

2.1.1. Sample for Studying Effect of Soybean Genotype on Isoflavone Content. This sample comprised sound seeds of all 14 varieties planted on 19 December 2009.

2.1.2. Sample for Studying Effect of Planting Date on Isoflavone Content. This sample was drawn from the sound seeds of all 14 varieties planted on all three dates.

2.1.3. Sample for Studying Effect of Physical Seed Quality on Isoflavone Content. The planting date of 19 December 2009 contributed the soybeans for determining the effect of physical seed quality on isoflavone content. The sample comprised all 14 soybean varieties and all three categories of physical seed quality (undersized, unsound, and sound). 


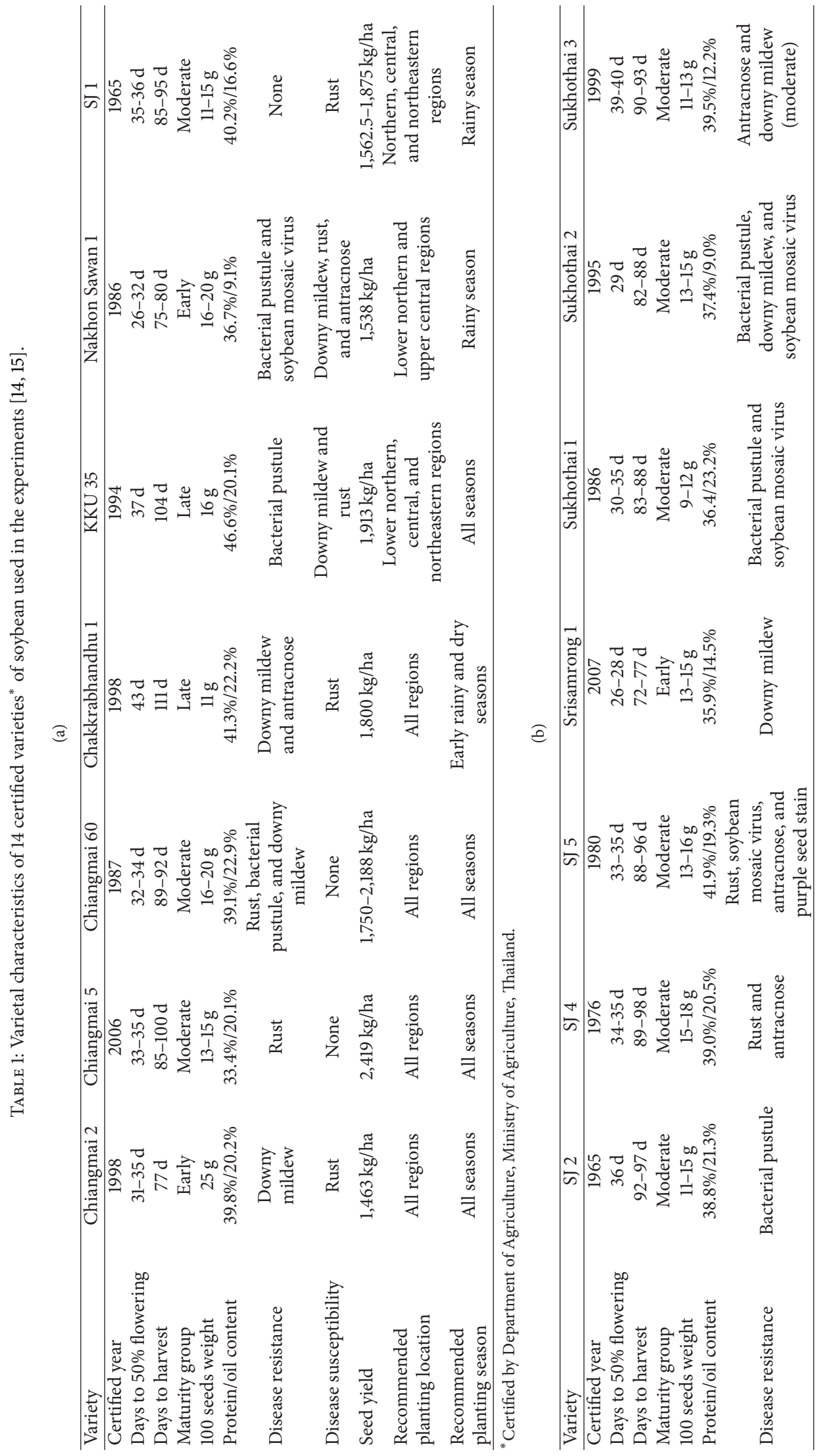




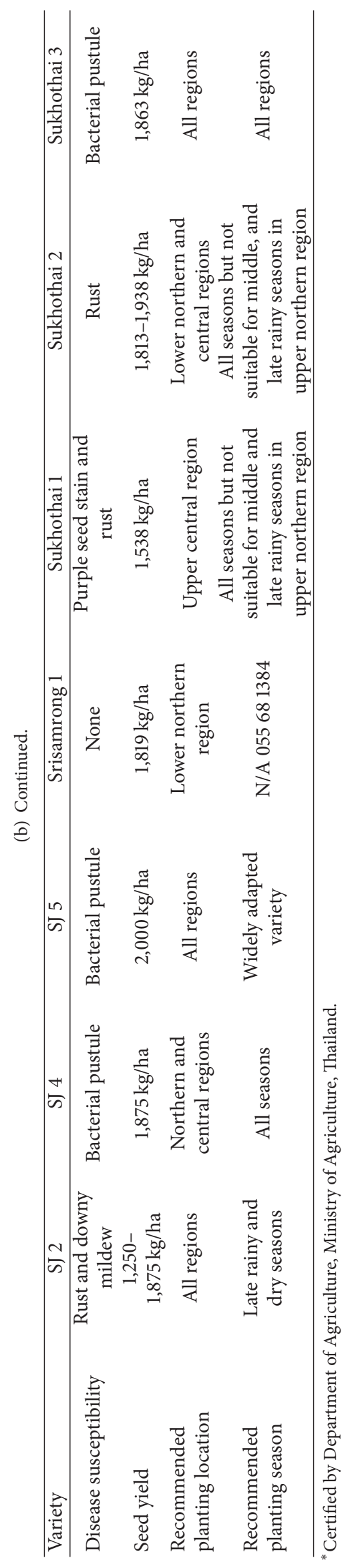


2.1.4. Sample for Studying Effect of Storage Condition on Isoflavone Content. Sound seeds of the 14 soybean varieties grown on 19 December 2009 were randomized into 2 portions. One portion was packed in heat-sealed plastic bags and refrigerated at $10^{\circ} \mathrm{C}$. The other portion was packed in paper bags and stored under ambient condition. After 18 months of storage, on 7 February 2012, both portions were analyzed for isoflavone content. The results were then compared with baseline values obtained in mid-August 2010 (see above).

\subsection{Description of Chiangmai 60 from \\ 4 Agricultural Research Centers}

2.2.1. Sample for Studying Effect of Planting Location on Isoflavone Content and Its Correlation to Seed Viability. The sample consisted of 38 lots of sound seeds of Chiangmai 60 grown in dry season of crop year 2010 at 4 agricultural research centers located in 4 different regions of Thailand. The name, location, and contribution of the centers were as follows: Chiang Mai Field Crops Research Center, upper northern region $\left(18^{\circ} 14^{\prime} \mathrm{N}, 92^{\circ} 3^{\prime} \mathrm{E}\right), 17$ lots; Phitsanulok Agricultural Research and Development Center, lower northern region $\left(16^{\circ} 15^{\prime} \mathrm{N}, 100^{\circ} 23^{\prime} \mathrm{E}\right), 15$ lots; Loei Agricultural Research and Development Center, north-eastern region $\left(17^{\circ} 24^{\prime} \mathrm{N}\right.$, $\left.101^{\circ} 44^{\prime} \mathrm{E}\right), 4$ lots; and Lop Buri Agricultural Research and Development Center, central region $\left(14^{\circ} 17^{\prime} \mathrm{N}, 100^{\circ} 50^{\prime} \mathrm{E}\right), 2$ lots. All seeds were refrigerated in heat-sealed plastic bags until the determination of isoflavone content and seed viability in mid-August 2010 (see below). The relationship between seed viability (determined by percentage of seed field emergence) and isoflavone content was then analyzed for correlation.

2.2.2. Sample for Studying Effect of Crop Year on Isoflavone Content. Chiang Mai Field Crops Research Center provided 30 lots of sound seeds of Chiangmai 60, all grown in dry season as follows: crop year 2010 (17 lots), crop year 2009 (5 lots), and crop year 2008 (8 lots). All seeds were refrigerated in heat-sealed plastic bags until analysis in mid-August 2010.

2.2.3. Determination of Seed Field Emergence. Seed viability was expressed as percentage of seed field emergence. All testing took place in concrete plots $19.0 \mathrm{~m} \times 0.80 \mathrm{~m}$ in a plasticroofed house at SUT Farm. The various soybean samples were hand-planted in three rows of 50 seeds each. The soil was sandy clay loam. The plots were watered immediately after planting and every day thereafter. Healthy seedlings were counted at 15 days after sowing.

2.3. Extraction and Quantification of Isoflavones in All Soybean Samples. Preparation of the soybean samples for isoflavone quantification followed a modification of methods taken from Barnes et al. [16] and from the AOAC Method [17]. Briefly, $200 \mathrm{mg}$ of raw soybeans with seed coat was ground, mixed with $10 \mathrm{~mL}$ of $80 \%$ methanol in water, sonicated for 30 minutes, and stirred for $24 \mathrm{~h}$ at room temperature. Next, $350 \mu \mathrm{L}$ of $2 \mathrm{M}$ of sodium hydroxide $(\mathrm{NaOH})$ was added and mixed, followed by $250 \mu \mathrm{L}$ of $100 \%$ acetic acid. One $\mathrm{mL}$ of this solution was centrifuged. Ten $\mu \mathrm{L}$ of clear supernatant was then mixed with $30 \mu \mathrm{L}$ of mobile phase B (see below) and spiked with $10 \mu \mathrm{L}$ of internal standard (IS, $50,000 \mathrm{ng} / \mathrm{mL}$ of fluorescine). Five $\mu \mathrm{L}$ of this mixture was injected into a high performance liquid chromatography (HPLC) system. Each soybean sample was extracted and assayed in triplicate.

The samples were analyzed on a C18 column (Inertsil, $150 \mathrm{~mm} \times 4$ 4.6 I.D., $5 \mu \mathrm{m}$, GL Science, Tokyo, Japan) with a C18 guard column (Inertsil ODS-3, $10 \mathrm{~mm} \times 4.0$ I.D., $5 \mu \mathrm{m}$, GL Science, Tokyo, Japan). The chromatography condition consisted of two mobile phases. Mobile phase A was $55 \mathrm{mM}$ ammonium acetate in distilled water/acetonitrile/ methanol $(250: 45: 45, \mathrm{v} / \mathrm{v} / \mathrm{v})$. Mobile phase B was $55 \mathrm{mM}$ ammonium acetate in distilled water/acetonitrile/methanol $(250: 255: 220, \mathrm{v} / \mathrm{v} / \mathrm{v})$. Both mobile phases contained $29 \mu \mathrm{L}$ of perchloric acid and $250 \mu \mathrm{L}$ of $1.44 \mathrm{mM}$ sodium dodecyl sulfate. Separation was performed at $25^{\circ} \mathrm{C}$. The flow rate of the mobile phase was maintained at $1 \mathrm{~mL} / \mathrm{min}$, and analyses were detected by UV absorption at $259 \mathrm{~nm}$. Standard isoflavones (daidzin, genistin, daidzein, and genistein) were spiked in serial dilution to obtain a standard calibration curve of 93.75 , $187.5,375,750,1500,3000$, and $6000 \mathrm{ng} / \mathrm{mL}$. The regression equations for testing the linearity of standard calibration curves were as follows:

$$
\begin{aligned}
& y=0.2373 x+0.0003\left(r^{2}=1\right) \text { for daidzin; } \\
& y=0.5115 x+2.5752\left(r^{2}=1\right) \text { for genistin; } \\
& y=0.2994 x+0.4664\left(r^{2}=0.9998\right) \text { for daidzein; } \\
& y=0.396 x+0.4456\left(r^{2}=0.9999\right) \text { for genistein. }
\end{aligned}
$$

The chromatogram of isoflavones and their retention times is shown in Figure 2(a). The isoflavone concentrations of unknown samples were determined by using a calibration curve of the peak height ratios of isoflavones and IS versus respective isoflavone concentrations with use of linear regression.

2.4. Assay Validation. Five quality control (QC) samples spiked at 3 different concentrations of daidzin, genistin, daidzein, and genistein $(281.25,2750$, and $5500 \mathrm{ng} / \mathrm{mL})$ were analyzed for intraday and interday assay validation. The average coefficient of intraday assay validation for daidzin, genistin, daidzein, and genistein was $2.41 \pm 1.64 \%, 1.63 \pm 1.00 \%, 3.01 \pm$ $2.02 \%$, and $2.03 \pm 0.47 \%$, respectively. The average coefficient of interday assay validation for daidzin, genistin, daidzein, and genistein was $1.43 \pm 0.58 \%, 1.90 \pm 0.68 \%, 1.99 \pm 1.35 \%$, and $1.70 \pm 0.73 \%$, respectively. The Lower limit of quantification (LLQ) was defined as the lowest concentration on the calibration curve $(93.75 \mathrm{ng} / \mathrm{mL})$ that could be measured with acceptable precision (coefficient of variation (CV) of less than $\pm 20 \%)$.

2.5. Statistical Analysis. The isoflavone content in the soybean samples was presented as mean \pm standard deviation. Differences among the sample means were analyzed by using one-way analysis of variance (ANOVA) with the post hoc least significant difference (LSD) test, $P<0.05$ being considered significant. The coefficient of determination value $\left(r^{2}\right)$, calculated by linear regression analysis, was used to evaluate 


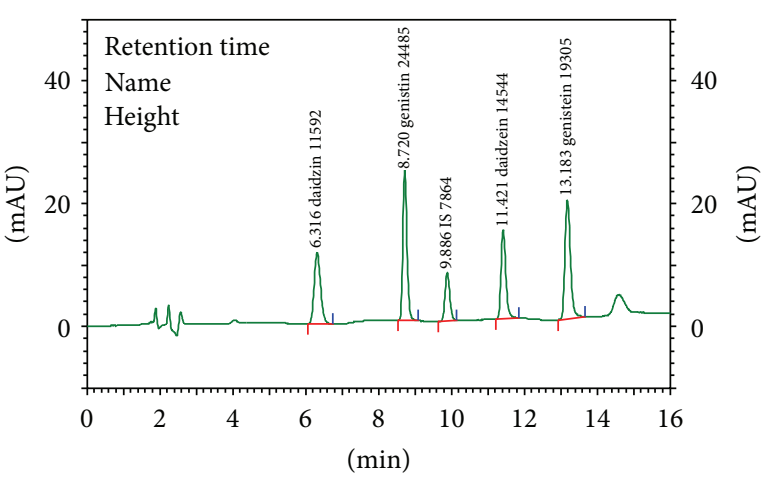

(a)

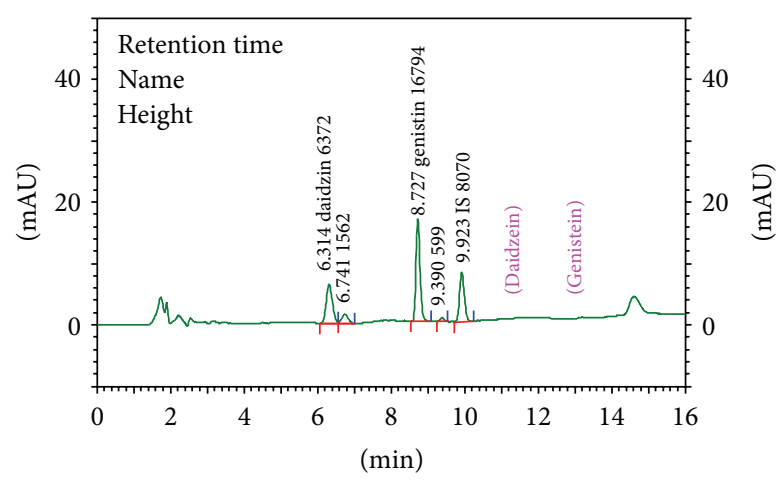

(b)

Figure 2: (a) Chromatogram of isoflavones in a standard mixture of daidzin, genistin, daidzein, and genistein $(6,000 \mathrm{ng} / \mathrm{mL}$, each) and internal standard (IS, fluorescein $10,000 \mathrm{ng} / \mathrm{mL}$ ). (b) Chromatogram of soybean seed sample (SJ 2 grown at SUT Farm) extracted with $80 \%$ methanol plus $2 \mathrm{M} \mathrm{NaOH}$.

the correlation between the percentages of field emergence and isoflavone content.

\section{Results and Discussion}

3.1. Isoflavone Profiles. The $\beta$-glycosides daidzin and genistin were the predominant forms of isoflavones found in all soybean samples. The corresponding aglycone forms of daidzein and genistein were undetectable, or detectable in negligible amounts in some soybean samples. Glycitin was not determined in this study. The chromatogram for soybean variety SJ 2 is representative of the study's findings (Figure 2(b)).

Previous studies have demonstrated that two malonyl glycosides ( $6^{\prime \prime}-O$-malonlydaidzin and $6^{\prime \prime}-O$-malonlygenistin) are the major isoflavone derivatives in soybean seeds [1820], whereas aglycone forms, which derive from enzymatic hydrolysis during fermentation, are the predominant forms in fermented soy foods, such as miso and tempeh [16, 21]. For this reason, none or only negligible amounts of the aglycone forms were detected in the unfermented soybean samples reported here and elsewhere [3].

However, the predominant forms of isoflavones extracted in the present study were the $\beta$-glycosides daidzin and genistin, instead of the malonyl glycosides, as previously reported elsewhere. This discrepancy resulted from the conversion of mostly malonyl glycosides to $\beta$-glycosides under the increased $\mathrm{pH}$ condition elicited by the application of $\mathrm{NaOH}$ during sample extraction [22]. Glycitein and its glycoside derivatives were not determined in this study due to their naturally smaller occurrence in soybeans $[2,3]$. Given the study's assay methodology and overall goals, the summation of daidzin and genistin contents would seem to provide a sufficiently accurate measure of the total isoflavone content of the soybean samples under analysis. The assay method is simple and easy to use. Its inability to differentiate malonyl and acetyl glycoside conjugates from $\beta$-glycoside conjugates seems a minor limitation, considering that such conjugate compounds are finally hydrolyzed to aglycone forms by $\beta$ glucosidase enzyme prior to human gastrointestinal absorption.
3.2. Effect of Seed Variety on Isoflavone Content. Among sound seeds of 14 soybean varieties grown under the same cultural practice on 19 December 2009, mean isoflavone content varied widely (Figure 3). Aglycone forms were undetectable except for varieties SJ 2, Sukhothai 3, and KKU 35, which showed trace amounts (approximately $0.017-0.039 \mathrm{mg} /$ g).

The lowest isoflavone yields were $0.34 \mathrm{mg} / \mathrm{g}$ of daidzin and $0.31 \mathrm{mg} / \mathrm{g}$ of genistin in the Sukhothai 1 variety, whereas the highest were $0.91 \mathrm{mg} / \mathrm{g}$ of daidzin and $1.08 \mathrm{mg} / \mathrm{g}$ of genistin in the SJ 2 variety. The mean isoflavone content in 11 out of 14 soybean varieties was significantly higher than that of the Sukhothai 1 variety.

Although environmental factors cannot be ruled out, the data derived from this study continue to emphasize the significant influence that soybean genotypes exert on isoflavone content. Previous work with 60 Korean varieties grown in Korea reported mean isoflavone values ranging from 1.62 to $2.52 \mathrm{mg} / \mathrm{g}$ [23], while a study of 210 soybean varieties grown in South Dakota, United States, found variations from 1.16 to 2.74 [24], and still another study of 7 American soybean varieties reported concentrations ranging from 2.05 to $4.22 \mathrm{mg} / \mathrm{g}$ [18]. In keeping with these previous results, the mean isoflavone content of Thai soybean varieties grown from sound seeds in Thailand was found to range widely from $0.65 \mathrm{mg} / \mathrm{g}$ (Sukhothai 1 grown at SUT Farm) to $2.75 \mathrm{mg} / \mathrm{g}$ (Chiangmai 60 obtained from Phitsanulok Agricultural Research and Development Center) (see below).

Morever, the daidzin: genistin ratio in 14 Thai soybean varieties investigated in this study varied from $1: 0.9$ to $1: 2.1$, which was comparable to the ratio of $1: 1.5$ to $1: 2$ in various soybean products, as reported in previous research [25]. Indeed, the proportion of genistin and its glycoside conjugates in soybeans might be of significant pharmacological importance, since genistein is a relatively potent agonist for the $\beta$-isoform of the estrogen receptor $(\operatorname{ER} \beta)$, which might explain its clinical efficacy, especially in postmenopausal health [26]. 


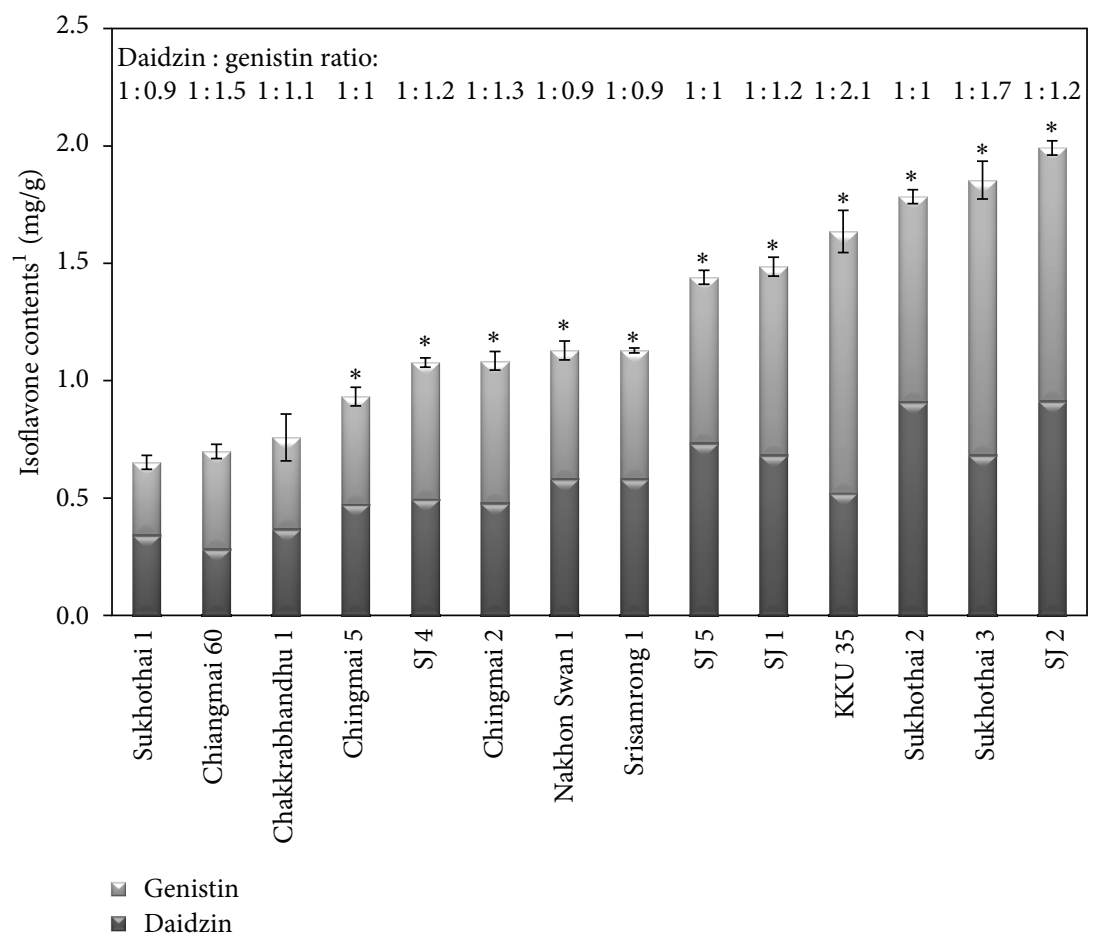

FIGURE 3: Isoflavone content in sound seeds of 14 soybean varieties planted at SUT Farm on 19 December 2009. Sound seeds of each soybean variety were extracted and assayed in triplicate $(n=3)$. Bars and error bars represent mean \pm standard deviation. ${ }^{*} P<0.05$ compared to Sukhothai $1 .{ }^{1}$ Isoflavone content was the summation of daidzin and genistin contents.

TABLE 2: Isoflavone content ${ }^{1}(\mathrm{mg} / \mathrm{g})$ in sound seeds of 14 soybean varieties planted on different dates in the same crop year at SUT Farm.

\begin{tabular}{|c|c|c|c|}
\hline \multirow{2}{*}{ Variety } & \multicolumn{3}{|c|}{ Planting date } \\
\hline & 19 December 2009 & 26 December 2009 & 15 January 2010 \\
\hline Chiangmai 2 & $1.08 \pm 0.04$ & $0.68 \pm 0.02^{*}$ & $0.38 \pm 0.01^{* \dagger}$ \\
\hline Chiangmai 5 & $0.93 \pm 0.04$ & $0.60 \pm 0.02^{*}$ & $0.41 \pm 0.03^{* \dagger}$ \\
\hline Chiangmai 60 & $0.70 \pm 0.03$ & $0.90 \pm 0.04^{*}$ & $0.34 \pm 0.02^{* \dagger}$ \\
\hline Chakkrabhandhu 1 & $0.76 \pm 0.10$ & $0.64 \pm 0.04$ & ND \\
\hline KKU 35 & $1.65 \pm 0.09$ & $1.22 \pm 0.02^{*}$ & ND \\
\hline Nakhon Sawan 1 & $1.13 \pm 0.04$ & $1.52 \pm 0.04^{*}$ & $1.50 \pm 0.05^{*}$ \\
\hline SJ 1 & $1.49 \pm 0.04$ & $1.36 \pm 0.01^{*}$ & $0.82 \pm 0.01^{* \dagger}$ \\
\hline SJ 2 & $1.99 \pm 0.03$ & $2.02 \pm 0.04$ & $0.70 \pm 0.05^{* \dagger}$ \\
\hline SJ 4 & $1.08 \pm 0.02$ & $1.16 \pm 0.08$ & $0.67 \pm 0.05^{* \dagger}$ \\
\hline SJ 5 & $1.44 \pm 0.03$ & $1.28 \pm 0.08^{*}$ & $0.55 \pm 0.04^{* \dagger}$ \\
\hline Srisamrong 1 & $1.15 \pm 0.01$ & $1.19 \pm 0.03^{*}$ & $0.78 \pm 0.01^{* \dagger}$ \\
\hline Sukhothai 1 & $0.65 \pm 0.03$ & $1.68 \pm 0.06^{*}$ & $0.99 \pm 0.03^{* \dagger}$ \\
\hline Sukhothai 2 & $1.78 \pm 0.03$ & $0.71 \pm 0.01^{*}$ & $0.44 \pm 0.01^{* \dagger}$ \\
\hline Sukhothai 3 & $1.88 \pm 0.08$ & $0.91 \pm 0.03^{*}$ & $1.10 \pm 0.05^{* \dagger}$ \\
\hline Mean \pm SD & $1.27 \pm 0.44$ & $1.13 \pm 0.42$ & $0.72 \pm 0.34^{* \dagger}$ \\
\hline
\end{tabular}

Each soybean sample was extracted and assayed in triplicate $(n=3)$. Data represent mean \pm standard deviation. ${ }^{*} P<0.05$ compared to 19 December 2009 . ${ }^{\dagger} P<0.05$ compared to 26 December 2009. ND: not determined due to lack of soybean seed samples. ${ }^{1}$ Isoflavone content was the summation of daidzin and genistin contents.

3.3. Effect of Planting Date in the Same Crop Year on Isoflavone Content in 14 Soybean Varieties. Isoflavone content in sound seeds of 14 soybean varieties planted under the same cultural practice on 19 December 2009, 26 December 2009, and 15 January 2010 is shown in Table 2. Mean isoflavone content ranged from 0.72 to $1.27 \mathrm{mg} / \mathrm{g}$, with the cohort of 15 January 2010 generally expressing a significantly lower value than those of 19 December 2009 and 26 December 2009. However, 2 soybean varieties (Nakhon Sawan 1 and Sukhothai 1) planted on 15 January 2010 had significantly 


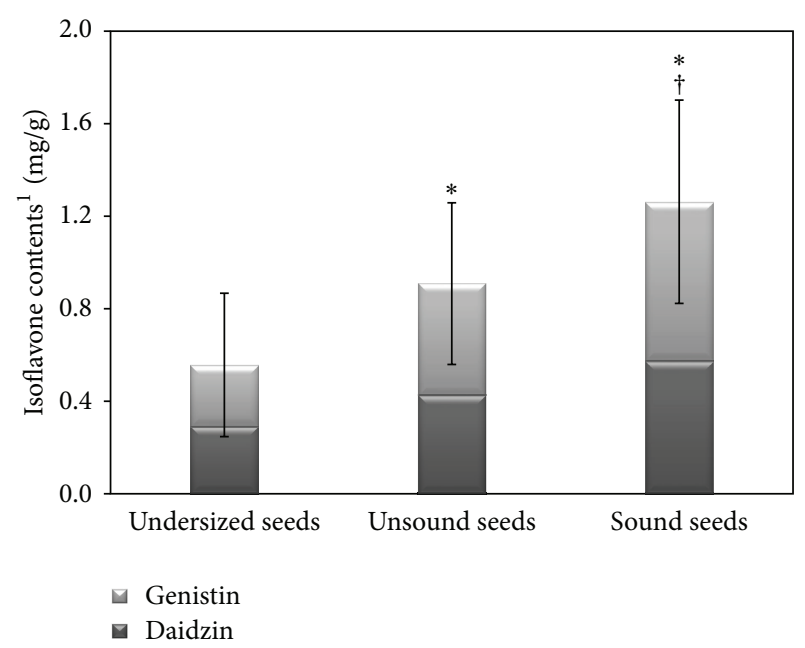

FIGURE 4: Isoflavone content in 14 soybean varieties planted at SUT Farm on 19 December 2009, categorized according to physical seed quality. Each soybean sample was extracted and assayed in triplicate $(n=3)$. Bars and error bars represent mean \pm standard deviation. ${ }^{*} P<0.05$ compared to undersized seeds. ${ }^{\dagger} P<0.05$ compared to unsound seeds. ${ }^{1}$ Isoflavone content was the summation of daidzin and genistin contents.

higher mean values than those planted on 19 December 2009.

The Thai Department of Agriculture has generally encouraged farmers to plant soybeans early in dry season [15], as late sowing increases the risk of exposing the crop to rain and higher temperatures, thereby leading to seed deterioration and smaller harvests. Early sowing in dry season also usually means that the soybean crop will be exposed to lower temperatures during the seed-ripening phase. As Tsukamoto et al. [27] have found that such climatic conditions can significantly increase total isoflavone yields. The present study appeared to support these findings by demonstrating how earlier planting dates of only a few weeks during the December-January dry season of 2009-2010 significantly affected mean isoflavone content. To achieve maximum isoflavone yields, it therefore seems imperative to match soybean variety with appropriate planting date. In addition, Nakhon Sawan 1 appears to be of special interest because in this study it persistently exhibited moderately high isoflavone content regardless of sowing date or environment. Seguin et al. [13] also identified soybean varieties with consistently high and low isoflavone content when grown across a range of environments. Further studies are warranted to confirm the advantages of Nakhon Sawan 1 and to identify the most appropriate planting dates for Thai soybean varieties in each season.

3.4. Effect of Physical Seed Quality on Isoflavone Content in 14 Soybean Varieties. Mean isoflavone content in undersized seeds, unsound seeds, and sound seeds of 14 soybean varieties planted on 19 December 2009 under the same cultural practice is presented in Figure 4. The mean value in sound seeds was significantly greater than in unsound seeds and

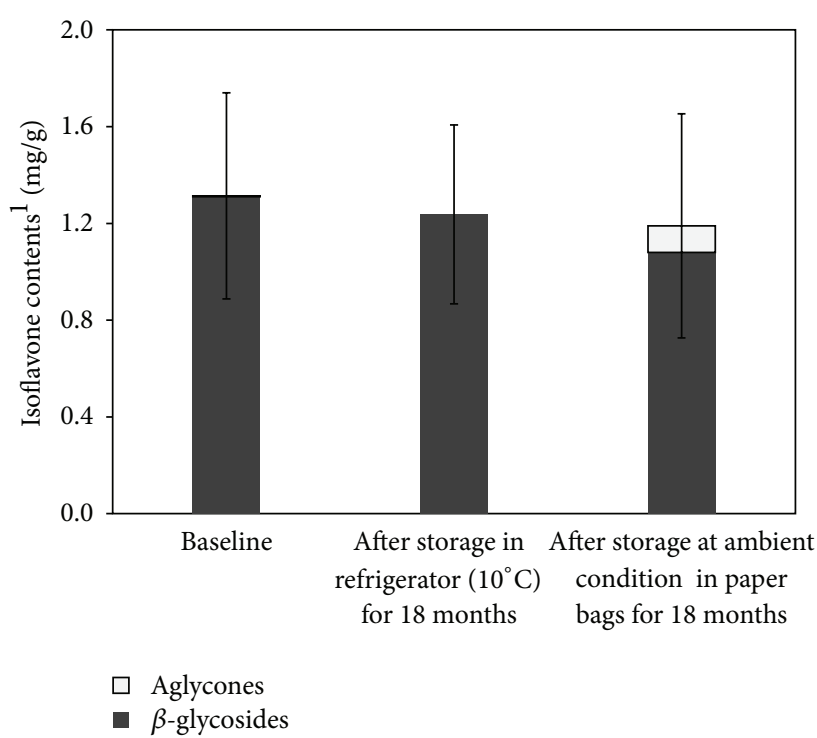

FIGURE 5: Isoflavone content in sound seeds of 14 soybean varieties planted at SUT Farm on 19 December 2009, at baseline and after storage under different conditions. Sound seeds of each soybean variety were extracted and assayed in triplicate. Bars and error bars represent mean \pm standard deviation. ${ }^{1}$ Isoflavone content was the summation of daidzin and genistin contents.

undersized seeds. Similarly, the mean value in unsound seeds was significantly greater than in undersized seeds. These findings suggest that selection of sound seeds as raw materials in the manufacturing of soy and soy-based products is essential for isoflavone-rich food products. Generally, undersized seeds are young seeds at R5-R6 (beginning seed to green fullsize seed) stages. These stages coincide with the beginning of isoflavone production [28]. Total isoflavone concentrations are lowest at R5 but increase steadily, reaching their peak at R8 (harvest maturity) stage. Therefore, lower isoflavone yields should be expected from soybean varieties producing high percentages of undersized seeds, whether as a response to environmental conditions inhibiting the development of seed maturity or as a result of indeterminate growth habit. Determinate soybean varieties start flowering at all node almost at the same time when the plants have reached maximum height, and the addition of node number on the main stem ceases abruptly at R1. In contrast, indeterminate varieties start flowering, when the plants have reached 30$50 \%$ of their maximum height, and still continue to increase both vegetative growth and height, while the node number on the main stem stops at R5. This results in a longer duration of flowering and prolonged ripening period in the indeterminate varieties $[29,30]$. Accordingly, variation in seed size within a seed lot is greater in indeterminate varieties than that of determinate varieties [31].

3.5. Effect of Storage Condition on Isoflavone Content in 14 Soybean Varieties. Mean isoflavone contents in sound seeds of 14 soybean varieties stored under different conditions for 18 months were compared to mean values at baseline (Figure 5). The various samples showed no significant 

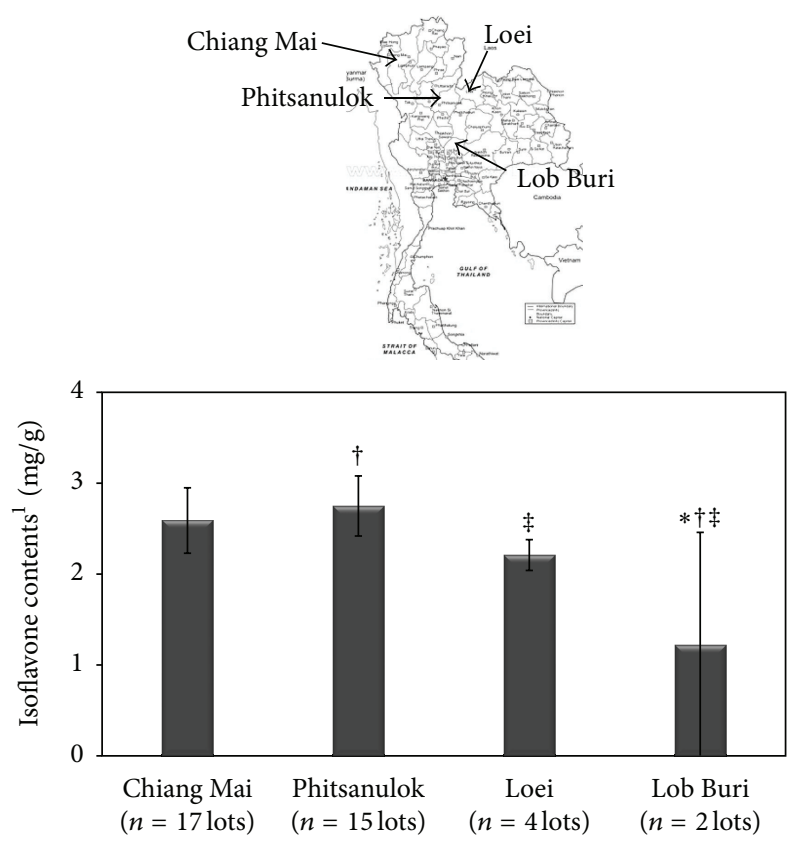

FIGURE 6: Isoflavone content in sound seeds of Chiangmai 60 soybean variety grown in dry season crop year 2010 and obtained from 4 agricultural research centers in Thailand. The soybean samples from each site were from different lots. Each lot was extracted and assayed in triplicate. ${ }^{*} P<0.05$ compared to Chiang Mai province. ${ }^{\dagger} P<0.05$ compared to Loei province. ${ }^{\ddagger} P<0.05$ compared to Phitsanulok province. Bars and error bars represent mean \pm standard deviation. ${ }^{1}$ Isoflavone content was the summation of daidzin and genistin contents.

differences, whether they were refrigerated at $10^{\circ} \mathrm{C}$ for 18 months or stored at ambient condition for the same period. This observation is in agreement with previous research which investigated the effects of soybean storage at $5^{\circ} \mathrm{C}$ for 18 months [32].

However, long-term exposure to ambient condition caused a slight increase in the aglycone forms of isoflavones (daidzein and genistein) in comparison to the negligible amounts detected at baseline or after equivalent long-term refrigeration. The increased proportion of aglycones after long-term storage at ambient condition in this study suggests that this phenomenon possibly results from a spontaneous conversion of some glycoside conjugates to aglycones. This conversion seems unlikely to affect the benefits of soybeans consumption because the oral bioavailability of aglycones and glycoside conjugates is equivalent [33]. In contrast, a Korean study of soybean varieties has shown that a longer storage period of 3 years does significantly decrease isoflavone content for samples stored at both a lower temperature of $-30^{\circ} \mathrm{C}$ and at ambient condition [20]. This research should be replicated using Thai varieties.

3.6. Effect of Planting Location on Isoflavone Content in Chiangmai 60. Mean isoflavone content in sound seeds of Chiangmai 60 grown in the crop year 2010 at 4 different research centers is presented in Figure 6. Values varied significantly

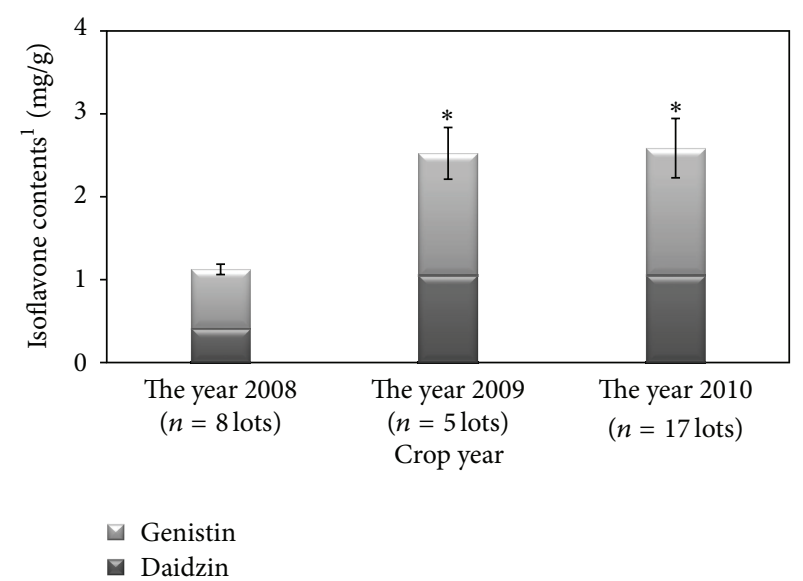

FIgURE 7: Isoflavone content in sound seeds of Chiangmai 60 soybean variety grown in different crop years and obtained from Chiang Mai Field Crops Research Center. The soybean samples from each crop year were obtained from different lots. Each lot was extracted and assayed in triplicate. ${ }^{*} P<0.05$ compared to the year 2008. Bars and error bars represent mean \pm standard deviation. ${ }^{1}$ Isoflavone content was the summation of daidzin and genistin contents.

from $1.22 \pm 1.24$ to $2.75 \pm 0.33 \mathrm{mg} / \mathrm{g}$. Such values were comparable to previously reported variations of 1.18 to $1.75 \mathrm{mg} / \mathrm{g}$ for a single variety (Vinton 81 ) from different locations in Iowa, USA [18]. The highest isoflavone concentrations were found in the samples from Phitsanulok Province, followed by Loei Province, Chiang Mai Province, and Lop Buri Province, respectively. Soybean seeds obtained from Lob Buri Agricultural Research and Development Center in 2010 gave the lowest isoflavone content, perhaps reflecting the higher temperatures customary at Lob Buri during soybean maturation, as compared to temperatures at the other locations situated at lower latitudes.

3.7. Effect of Crop Year on Isoflavone Content in Chiangmai 60. Mean isoflavone content in sound seeds of Chiangmai 60 grown in different crop years at the same location is shown in Figure 7. Values ranged from 1.05 to $1.21 \mathrm{mg} / \mathrm{g}$ in 2008 , 2.27 to $2.95 \mathrm{mg} / \mathrm{g}$ in 2009 , and 1.79 to $3.17 \mathrm{mg} / \mathrm{g}$ in 2010 . Plantings from crop year 2008 were significantly lower in mean isoflavone content than those from crop years 2009 and 2010. These data suggest the remarkable influence of differing crop years on isoflavone content [11]. Again, such values were in accordance with previously reported variations of 1.18 to $3.30 \mathrm{mg} / \mathrm{g}$ for soybeans grown in Iowa in different years [18].

3.8. Correlation between Percentage of Seed Field Emergence and Isoflavone Content in Chiangmai 60. Figure 8 depicts the correlation between percentage of seed field emergence and isoflavone content in 38 different lots of Chiangmai 60 grown in the crop year 2010. The percentage of field emergence in these soybean samples ranged from 17 to $79 \%$ (average $56.88 \pm 16.01 \%)$. There was no correlation between these parameters $\left(r^{2}=0.186\right)$. Furthermore, Thai soybeans in this study remained stable in isoflavone content regardless of 


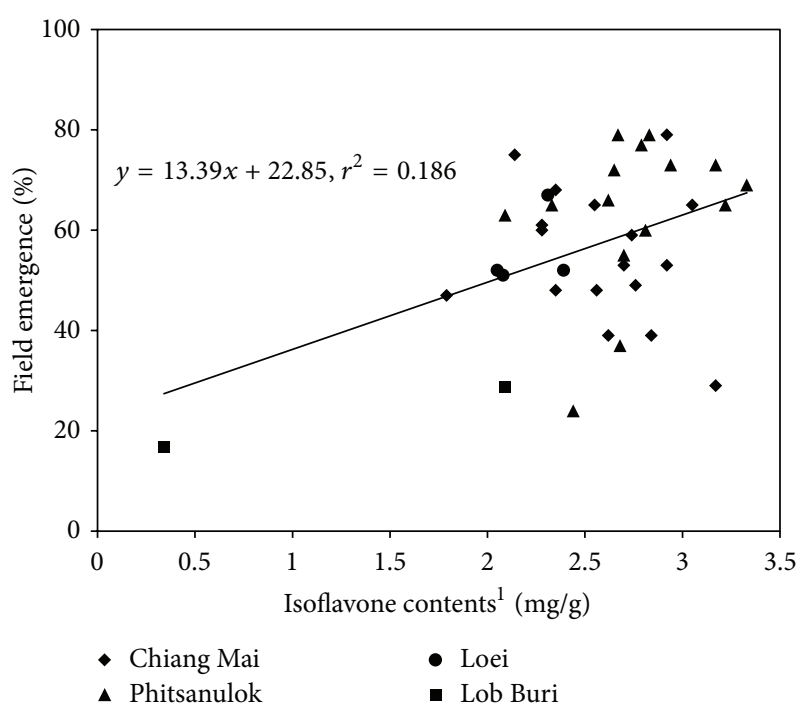

FIGURE 8: The coefficient of determination value $\left(r^{2}\right)$ calculated by linear regression analysis between percentages of seed field emergence and total isoflavone content in sound seeds of Chiangmai 60 soybean variety grown in dry season crop year $2010(n=38$ different lots) and obtained from 4 agricultural research centers in Thailand. Each lot was extracted and assayed in triplicate. ${ }^{1}$ Isoflavone content was the summation of daidzin and genistin contents.

storage conditions within 18 months (see above). It therefore appears that leftover soybean seeds from seed shops or warehouses that are no longer suitable for planting can still be used as raw materials in the manufacturing of soy and soybased products without sacrificing isoflavone content.

3.9. Study Limitations. Although isoflavone values reported here seemed sufficiently accurate for the study's comparative purposes, it must be noted that the lack of measurement of glycitin and its derivatives underestimated total isoflavone content by $5-10 \%$. Similarly, the use of $\mathrm{NaOH}$ in the quantification assay probably depressed isoflavone values in some degree because of possible incomplete conversion of malonyl and acetyl glycoside conjugates to their respective daidzin or genistin forms. Finally, the investigation of differential planting dates on isoflavone content was conducted within a short period of time represented by dry season December 2009 to January 2010. Other planting dates in other seasons should be further investigated.

\section{Conclusions}

Isoflavone content in Thai soybeans varied considerably depending on multiple genetic and environmental factors such as variety, physical seed quality, crop year, planting date (even in the same crop year), and planting location. Nonetheless, some striking varieties (Nakhon Sawan 1 and Sukhothai 1) exhibited moderately high isoflavone content regardless of sowing date. Furthermore, soybeans with decreased seed viability were shown to retain their isoflavone content.

\section{Acknowledgments}

This work was supported by the Faculty of Medicine, Chiang Mai University, Thailand. The authors are grateful for the editorial assistance of Jeffrey Hess, an English language consultant under contract with the Faculty of Medicine, Chiang Mai University. The authors would also like to acknowledge Ms. Sujitra Techatoei for her assistance in extraction and quantification of isoflavones in all soybean samples.

\section{References}

[1] K. D. R. Setchell, "Phytoestrogens: the biochemistry, physiology, and implications for human health of soy isoflavones," The American Journal of Clinical Nutrition, vol. 68, no. 6, pp. 1333S1346S, 1998.

[2] T. Song, K. Barua, G. Buseman, and P. A. Murphy, "Soy isoflavone analysis: quality control and a new internal standard," The American Journal of Clinical Nutrition, vol. 68, no. 6, pp. 1474S-1479S, 1998.

[3] S. Jung, P. A. Murphy, and I. Sala, "Isoflavone profiles of soymilk as affected by high-pressure treatments of soymilk and soybeans," Food Chemistry, vol. 111, no. 3, pp. 592-598, 2008.

[4] A. Atmaca, M. Kleerekoper, M. Bayraktar, and O. Kucuk, "Soy isoflavones in the management of postmenopausal osteoporosis," Menopause, vol. 15, no. 4, pp. 748-757, 2008.

[5] D.-F. Ma, L.-Q. Qin, P.-Y. Wang, and R. Katoh, "Soy isoflavone intake increases bone mineral density in the spine of menopausal women: meta-analysis of randomized controlled trials," Clinical Nutrition, vol. 27, no. 1, pp. 57-64, 2008.

[6] S.-H. Li, X.-X. Liu, Y.-Y. Bai et al., "Effect of oral isoflavone supplementation on vascular endothelial function in postmenopausal women: a meta-analysis of randomized placebocontrolled trials," The American Journal of Clinical Nutrition, vol. 91, no. 2, pp. 480-486, 2010.

[7] C. R. Cederroth and S. Nef, "Soy, phytoestrogens and metabolism: a review," Molecular and Cellular Endocrinology, vol. 304, no. 1-2, pp. 30-42, 2009.

[8] R. D. 'Anna, M. L. Cannata, H. Marini et al., "Effects of the phytoestrogen genistein on hot flushes, endometrium, and vaginal epithelium in postmenopausal women: a 2-year randomized, double-blind, placebo-controlled study," Menopause, vol. 16, no. 2, pp. 301-306, 2009.

[9] V. S. Lagari and S. Levis, "Phytoestrogens and bone health," Current Opinion in Endocrinology, Diabetes and Obesity, vol. 17, no. 6, pp. 546-553, 2010.

[10] D. Zhu, N. S. Hettiarachchy, R. Horax, and P. Chen, "Isoflavone contents in germinated soybean seeds," Plant Foods for Human Nutrition, vol. 60, no. 3, pp. 147-151, 2005.

[11] J. A. Hoeck, W. R. Fehr, P. A. Murphy, and G. A. Welke, "Influence of genotype and environment on isoflavone contents of soybean," Crop Science, vol. 40, no. 1, pp. 48-51, 2000.

[12] S. J. Lee, W. Yan, J. K. Ahn, and I. M. Chung, "Effects of year, site, genotype and their interactions on various soybean isoflavones," Field Crops Research, vol. 81, no. 2-3, pp. 181-192, 2003.

[13] P. Seguin, W. Zheng, D. L. Smith, and W. Deng, "Isoflavone content of soybean cultivars grown in eastern Canada," Journal of the Science of Food and Agriculture, vol. 84, no. 11, pp. 13271332,2004

[14] B. Jumroonpong, W. Somprasong, and P. Pankhaew, Plant Germplasm Database, Department of Agriculture, Ministry of 
Agriculture and Cooperatives, The Agricultural Cooperatives Federation of Thailand, 2004.

[15] S. Inthipong and R. Sopa, Soybean Cultivation, Department of Agriculture, Ministry of Agriculture and Cooperatives, Idea Square, Thailand, 2004.

[16] S. Barnes, M. Kirk, and L. Coward, "Isoflavones and their conjugates in soy foods: extraction conditions and analysis by HPLC-mass spectrometry," Journal of Agricultural and Food Chemistry, vol. 42, no. 11, pp. 2466-2474, 1994.

[17] AOAC official method 2001.10, Determination of Isoflavones in Soy and Selected Foods Containing Soy. Extraction, Saponification and Liquid Chromatography: Official Methods of Analysis, 17th edition, 2000.

[18] H.-J. Wang and P. A. Murphy, "Isoflavone composition of American and Japanese soybeans in Iowa: effects of variety, crop year, and location," Journal of Agricultural and Food Chemistry, vol. 42, no. 8, pp. 1674-1677, 1994.

[19] S. Kudou, Y. Fleury, D. Welti et al., "Malonyl isoflavone glycosides in soybean seeds (Glycine max Merrill)," Agricultural and Biological Chemistry, vol. 55, pp. 2227-2233, 1991.

[20] J. J. Kim, S. H. Kim, S. J. Hahn, and I. M. Chung, "Changing soybean isoflavone composition and concentrations under two different storage conditions over three years," Food Research International, vol. 38, no. 4, pp. 435-444, 2005.

[21] H.-J. Wang and P. A. Murphy, "Isoflavone content in commercial soybean foods," Journal of Agricultural and Food Chemistry, vol. 42, no. 8, pp. 1666-1673, 1994.

[22] V. Yerramsetty, K. Mathias, M. Bunzel, and B. Ismail, "Detection and structural characterization of thermally generated isoflavone malonylglucoside derivatives," Journal of Agricultural and Food Chemistry, vol. 59, no. 1, pp. 174-183, 2011.

[23] K. J. Yang and I. M. Chung, "Yearly and genotypic variations in seed isoflavone content of local soybean cultivars," Korean Journal of Crop Science, vol. 46, pp. 139-144, 2001.

[24] C. Wang, M. Sherrard, S. Pagadala, R. Wixon, and R. A. Scott, "Isoflavone content among maturity group 0 to II soybeans," Journal of the American Oil Chemists' Society, vol. 77, no. 5, pp. 483-487, 2000.

[25] J. J. B. Anderson, M. Anthony, M. Messina, and S. C. Garner, "Effects of phyto-oestrogens on tissues," Nutrition Research Reviews, vol. 12, no. 1, pp. 75-116, 1999.

[26] M. F. McCarty, “Isoflavones made simple-genistein's agonist activity for the beta-type estrogen receptor mediates their health benefits," Medical Hypotheses, vol. 66, no. 6, pp. 1093-1114, 2006.

[27] C. Tsukamoto, S. Shimada, K. Igita et al., "Factors affecting isoflavone content in soybean seeds: changes in isoflavones, saponins, and composition of fatty acids at different temperatures during seed development," Journal of Agricultural and Food Chemistry, vol. 43, no. 5, pp. 1184-1192, 1995.

[28] J.-A. Kim and I.-M. Chung, "Change in isoflavone concentration of soybean (Glycine max L.) seeds at different growth stages," Journal of the Science of Food and Agriculture, vol. 87, no. 3, pp. 496-503, 2007.

[29] S. Belfield, C. Brown, and M. Martin, Soybean: Guide to Upland Cropping in Cambodia, ACIAR Monograph no. 146, Australian Centre for International Agricultural Research, Canberra, Australia, 2011.

[30] P. Pedersen, "Soybean physiology: yield, maturity groups, and growth stages," 2013, http://www.plantmanagementnetwork .org/.
[31] D. B. Egli, R. A. Wiralaga, and E. L. Ramseur, "Variation in seed size in soybean," Agronomy Journal, vol. 79, no. 3, pp. 463-467, 1987.

[32] H. J. Hou and K. C. Chang, "Interconversions of isoflavones in soybeans as affected by storage," Journal of Food Science, vol. 67, no. 6, pp. 2083-2089, 2002.

[33] X. Xu, H.-J. Wang, P. A. Murphy, and S. Hendrich, "Neither background diet nor type of soy food affects short-term isoflavone bioavailability in women," Journal of Nutrition, vol. 130, no. 4, pp. 798-801, 2000. 


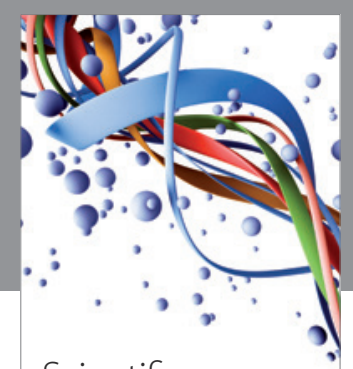

Scientifica
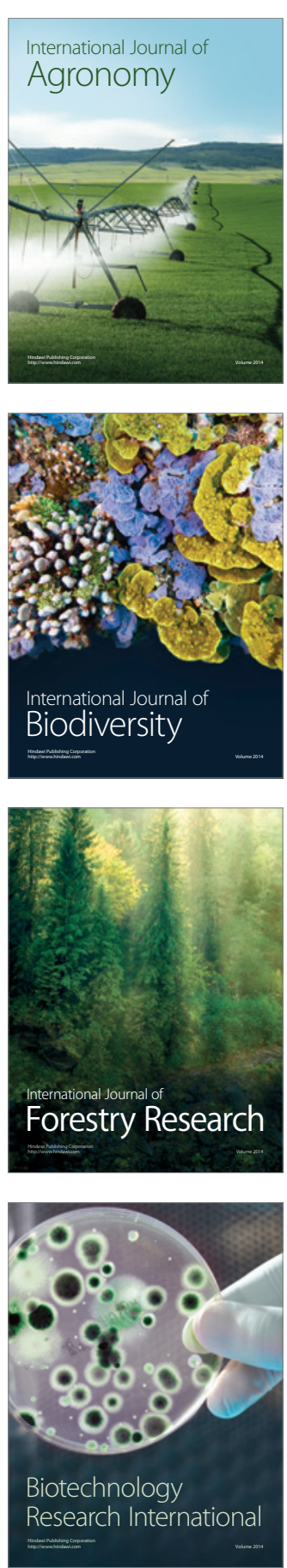
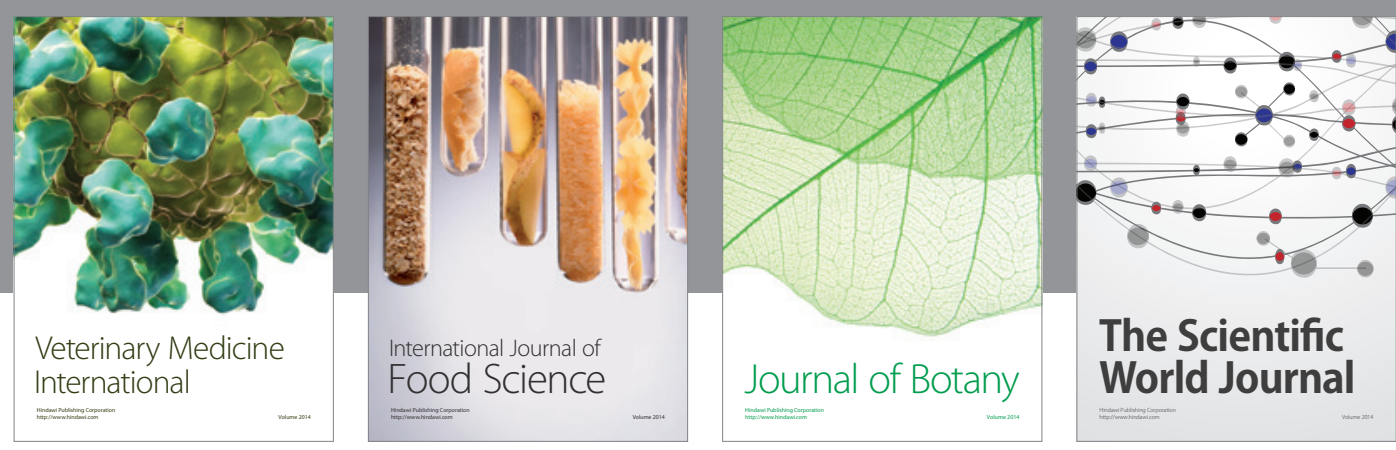

The Scientific World Journal
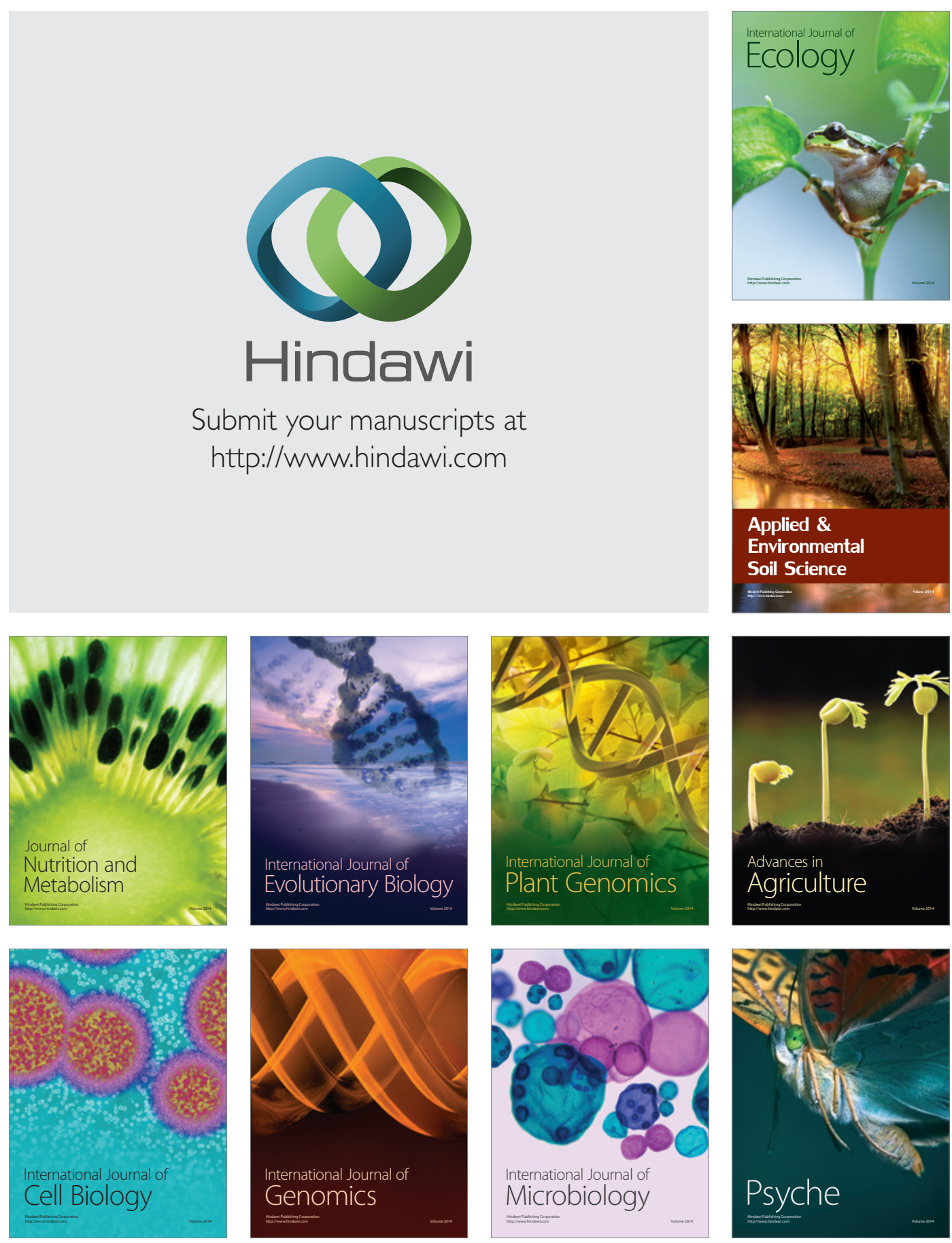